\title{
Teaching cultural literacies with films: Using the online platform Education on Screen in secondary school classrooms
}

\author{
Maarja Ojamaa* and Alexandra Milyakina - University of Tartu, Estonia
}

\begin{abstract}
This case study presents the Estonian open access online platform Education on Screen. So far, the platform features two educational projects: Literature on Screen and History on Screen. Both projects are aimed at secondary school students and are balanced between a thorough treatment of a single film and a universal framework for discussing the topics of film adaptation of literary texts and the mediated construction of historical memory. The focus is thus both on film literacy and on film as a means for developing cultural literacies. The projects combine accessibly written theoretical discussions from the perspective of cultural semiotics, excerpts from films, materials relating to their production and reception, analytical tasks, and assignments for implementing individual creativity in multimodal forms. Finally, this paper includes some conclusions drawn from testing the platform with 230 students during 2017/18.
\end{abstract}

Keywords: film literacy; cultural literacies; screen adaptation; literature class; history class

Education on Screen (www.haridusekraanil.ee) (EoS) is an open access online platform for educational projects targeted primarily at secondary school students in Estonia. It is being developed by the Transmedia Research Group (TRG) working at the Department of Semiotics at the University of Tartu. The authors of the present article are among the members of the group and have been actively involved with EoS and all the activities described below.

The initial motivation behind developing the platform stemmed from our wish to test certain aspects of theory by applying them in practice. More specifically, the cultural semiotic theory of Juri Lotman and the Tartu-Moscow Semiotic School allows for conceptualizing culture as education (see Ojamaa et al., 2019), a complex system that simultaneously bears the functions of memory and of creation, including the cultivation of literacies. The key issues we initially aimed to address were: (1) stronger integration of different humanities subjects to reflect the way arts are interrelated in culture; (2) supporting the treatment of visual and multimodal forms of culture to balance the verbocentric approaches still dominant in schools; and (3) offering the conceptual ground for implementing contemporary digital tools in schools. While the background of all six core members of the research group is within the semiotics of culture, we have also received pedagogical and didactic support from teachers and members of the Institute of Education at the University of Tartu. Several BA, MA and PhD students of the Department of Semiotics have also worked with us on various phases of the individual projects featured on the platform. The work has been funded by various grants from our home university, as well as by the Estonian Film Institute (EFI), while local film 
production companies have provided us with their creative and preparatory materials for free. Developments in the last few years have led us to believe that this undertaking will be sustainable within the foreseeable future: knowledge about, and interest in, our resources has risen among teachers; a course focused on the development of new content for the platform has appeared in the MA curriculum of semiotics and culture studies; and the Estonian Film Institute has been offering funds for projects related to film literacy. The students' contribution is especially valuable in this regard, as the core members of the research group seek to redirect their focus to conceptual and critical reflection and the contextualization of the materials.

The guiding motivation for creating and developing Education on Screen both agrees and disagrees with the first sentence of the first editorial of Film Education Journal (Chambers et al., 2018: 1): 'Film is a distinct medium with a distinct history and, as such, requires a distinct pedagogy.' On EoS, film is perceived as both a distinct medium and as a medium fundamentally interrelated to and with other media in culture. One aspect of the latter is film's genealogical connection to literature, theatre, photography and, perhaps less obviously, gaming (Strauven, 2011). One can also see connections in the opposite direction in the ways in which film influences contemporary literary culture, as exemplified by literary trailers or cover images of novels that have been adapted as films, or in the ways in which the conventions of the film medium (montage, framing, and so on) have affected the development of digital media (Manovich, 2001). As all media exist in a transmedial cultural space (Saldre and Torop, 2012), we propose that film education, and consequently film literacy, should account for the mediumspecificity of film, as well as for the convergence of film with other media in cultural mediation. In this article, we will concentrate more on the latter dimension - the ways in which film's interrelatedness with other (media) arts, and discursive practices more generally, have been explicated on EoS.

All the projects on the EoS platform started with films based on a previous literary text used to discuss different topics, including cinematic adaptation (Literature on Screen, kirjandus.haridusekraanil.ee, 2017), historical memory (History on Screen, ajalugu.haridusekraanil.ee/en, 2018) and identity (Identity on Screen, identiteet. haridusekraanil.ee/en, 2019). More specifically, we have sought to answer from a comparative perspective the question of how film remediates literary narratives, how film affects what we remember from the past (and what we forget about it) and, most recently, how film participates in the mediated construction of identities.

Each of the projects aims at presenting a general methodological framework for approaching the topics as well as a thorough treatment of one empirical example (explored in more detail below). Content is offered in a form that is decisively multimodal and includes: accessibly written theoretical starting points; verbal, visual, audio and audiovisual excerpts from each film; behind the scenes footage and material related to the reception of the films on public broadcasting channels and social media; excerpts from the novels from which the films are adapted; as well as analytical assignments, and individual and group tasks for implementing creativity in multimodal forms, such as telling stories in one's head in media other than verbal language (see Parry, 2010).

\section{Methodology}

The methodology informing how content is organized on Education on Screen stems from the cultural semiotics of Juri Lotman and the Tartu-Moscow Semiotic School (see Torop, 2015). The overall focus of this school has been a model of human culture that is simultaneously holistic and accounts for its immense internal heterogeneity 
(Lotman, 2001). Among the tools for this are the operational notions of 'text' and 'language' that are also employed on the platform. The concept of text describes any meaningful whole, regardless of its material of articulation. A film can, therefore, be analysed as a text, as can the trailers for a film as well as all films of a given director, insofar as they feature certain invariant elements and stylistic and conceptual continuities, thus forming the holistic oeuvre of a director. In this respect, 'text' is employed as an operational notion allowing for the analysability of various cultural phenomena. The notion of language here does not imply the existence of a static set of units and strict rules for their combination. Rather, it refers to an understanding of film as a system of communication and meaning-creation, and perhaps most importantly implies the need for learning. This is a presumption often forgotten due to the deceptively realistic appearance of film and other audiovisual media, thus frequently leading to a dangerous tendency to forget their mediated and constructed nature.

The notion of language seems logically to pave the way for the notion of literacy. In practical terms, film literacy (as framed on the EoS platform) refers to the ability to watch and analyse films critically, comprehend the process of film creation and understand the manner in which film functions in relation to other media within a broader cultural context. At the same time, adopting a similar approach to Burn and Durran (2007: 15), the materials on the EoS platform seek to account for both the rhetorical and aesthetic dimensions of literacies. Underlying this concept of film literacy is a concept of cultural literacy based on Lotman's (1971) conceptualization of two ways for learning culture. The first approach to learning (and teaching) culture regards culture as a sum of texts that are created within it, and bases the notion of cultural literacy upon a shared memory of a certain collection of texts. According to this viewpoint, one must be familiar with a set of canonical texts (including literary and film texts) in order to successfully communicate and participate in the life of a cultural community. The second approach regards culture as a set of languages used for meaning-making, and bases its notion of cultural literacy upon a command of the languages used for creating texts in a given culture. From this viewpoint, one requires a command of communicative systems and skills in order to understand texts articulated in these systems and produce them oneself. In a contemporary, digital cultural context, the second perspective is in line with what Cannon et al. (2018) have conceptualized as 'dynamic, playful and productive literacies'. The educational projects on EoS have sought to combine these two approaches. On the one hand, the projects feature thorough treatments of texts considered important in Estonian culture (including a contemporary bestseller, a canonical novel and an autobiographical treatment of the Stalinist era) and other texts linked to them intertextually. On the other hand, film, literature and other media are discussed as languages of culture that each employ their own means for making and mediating meaning. This methodological approach has also been motivated by the fact that the main target group for the projects includes not only native Estonian students, but also students whose home language is Russian and whose cultural memory is formed by a distinctively different set of texts.

In addition to this, the general approach of the platform to the learning process has been informed by the educational methodology of transmediation, as proposed by Charles Suhor in 1984. Suhor (1984: 250) defined transmediation as 'translation of content from one sign system into another'. Marjorie Siegel (1995: 461) has developed Suhor's approach and explains that: 'In transmediation, the learner does not simply correlate a content and an expression plane, but takes the interpretant arising from that correlation and maps it onto the expression plane of a new sign system.' The projects on EoS have followed suit by offering students who have read a novel and 
watched a film to model and express their understanding of the texts not only in terms of different modes and discourses of verbal sign systems, but also by means of visual and audial sign systems.

In what follows, we will offer a closer look at two of the projects on EoS (Literature on Screen and History on Screen) and the experience of testing them ourselves with 230 students at different schools.

\section{Case study: Literature on Screen}

\section{Aims and structure}

Literature on Screen is based on best-selling Estonian novel Old Barney or November (Rehepapp, ehk, November) by Andrus Kivirähk (2000) and its foreign-Oscar-nominated cinematic adaptation November by Rainer Sarnet (2017). Being deeply rooted in FinnoUgric folklore, the novel is characterized by multiple references to cultural context, and the same applies to the film. Both texts can be characterized as pseudo-historical fantasies set in a paganistic Estonian village in feudal times. The villagers, who live side by side with mythological creatures (werewolves, ghosts of the ancestors, and so on), are mostly occupied with stealing whatever and from whoever they can, including from each other, the landlord, the church and the devil. One of the very few exceptions is young Liina, who is in love with village boy Hans, who himself has fallen desperately for the unapproachable daughter of a local aristocrat. While Kivirähk's novel is a portrait of the whole village during one desolate November, Sarnet's film reorientates its focus towards the more individualistic love story. While Kivirähk is mostly known and celebrated for his peculiar style of humour, this love story aspect of the narrative is a dominant feature of Sarnet's black-and-white film.

The website of Literature on Screen includes a map of the storyworld and three theoretical sections: Film in Literature, Literature in Film, and Literature and Film in Culture. Each section offers a theoretical introduction, questions for discussion, interactive tasks, bibliography and ideas for creative projects. All content is divided into bite-sized modules that allow for customized lesson plans to be built for a variety of purposes. Students are encouraged not only to compare the source text to its adaptation, but also to embrace the whole life cycle of an adaptation, and indeed contribute their own interpretations by writing a script, choosing a soundtrack, making a mood board or something similar.

The first section, Film in Literature, begins with an acknowledgement that reading and understanding a literary text implies that certain mental images in various modalities are derived from previous cultural experience. Proceeding from this 'filmlike mental appearance' of a novel, actual films are explained as texts expressed in the language of film (Lotman, 1981), organized in accordance with medium-specific rules and conventions of meaning-making. The latter include the significance of sound, colour, variations of shot distances, movement or lack of movement of camera, and so on. In collaboration with the film production team, the semiotic framework for understanding film as language was combined with excerpts from November and its preparatory materials, some of which the students are able to manipulate (such as choosing a soundtrack for a scene, developing an alternative script, remixing the storyboard, and so on).

The second section, Literature in Film, focuses on the central mutual feature of literature and film - the narrative. Attention is paid to the question: What happens to a story and its constitutive elements (storyworld, characters) when it is translated 
from literary to film language? At the same time, the variations between the two are explained not only in terms of the different materials and conventions of the two media languages, but also in terms of the poetics and style chosen by the authors. Special attention is paid to the concept of the 'dominant' (Jakobson, 1981), which ensures the coherence of the whole: students are asked to compare the dominants of the film, its trailer and poster. In this section, students also get acquainted with the preparatory materials for the process of casting non-professional actors for November and have the chance of playing a guessing game based on the outcome.

The third section, Film and Literature in Culture, draws attention to the diversity of the meta- and inter-communicational relations between a given text and the several texts that precede and follow it chronologically. Within this framework, it is possible to distinguish the invariant aspects of the story, or the storyworld, and those elements that do vary between different media and discourses. The marketing campaign and the creative reception of the adaptation also belong to the transmedial text of such a whole (see Scolari, 2013).

The interactive map combines the storyworlds of the novel and the film with contextual information. It can be used as preparatory material before watching the film, or for facilitating a discussion in class afterwards. The map was added to the website later than the three parts described above in order to tackle culturally specific difficulties that occurred during the testing.

\section{Testing}

We have tested the platform ourselves with over two hundred students in five schools in Estonia, in both Estonian-speaking and Russian-speaking classes. It is worth mentioning that the Estonian school system is generally Estonian-language based, although schools in some regions are largely Russian-speaking, with at least 40 per cent of subjects taught in Russian. Lesson plans were tailored to the needs and conditions of each school: the course was divided into three lesson periods of 45 minutes or 75 minutes. Wherever possible, teaching was accompanied by a screening of November.

In all cases, the course included at least one creative task from each section of the platform. The current case study analyses the implementation of three tasks. Task 1 deals with the problem of mediation: students are asked to create a mood board based on an excerpt from the novel. Task 2 invites learners to mimic the logic of the film-maker and come up with an idea for a new character for the film. For Task 3 , students visualized their own version of a kratt - a supernatural creature in Estonian folklore that typically stole and acquired desirable goods for its master.

\section{Task 1: Mood board}

The first task is carried out individually, either in class or at home. The task requires that students notice their own internal, mental images while reading some pre-selected excerpts from the novel, before remediating these in the form of a mood board. The excerpts for this task depict the arrival of ghosts of village ancestors. The students are asked to define at least five keywords describing the scene and use them to search for suitable pictures using Google Images. The images are then put into a collage with the help of a preferred digital application (for example, Fotor). After the assignment is completed, students watch the corresponding scene of the film and engage in a discussion. The task models the processes that are taking place during an actual adaptation of a literary text. Similar to film-makers themselves, students are asked to define the most crucial elements of the storyworld and translate them into a different 
medium. In addition, the students can familiarize themselves with the collage-like preproduction materials compiled by the production team of November.

The outcomes of the testing were varied (see Figure 1 for an example). The mood boards created by the students featured styles from new gothic to childishly comical, from archival to what seemed purely random. Most students succeeded in finding appropriate images and even tried to adhere to the historical time and space of the novel. To make their mood boards more integrated, students chose a dominant colour theme (usually black-and-white, grey and dark brown), used images of a similar style, and sometimes even used visual editing tools to blend the images together. Several mood boards included intertextual references to other works of art, such as historical photographs, paintings and films. At the same time, hardly any student attempted to translate the comical literary style of Kivirähk: they focused on what was mediated, but not on how it was done. Thus, one of the key conclusions we drew from these observations is the necessity of developing the ability to differentiate between content and form.

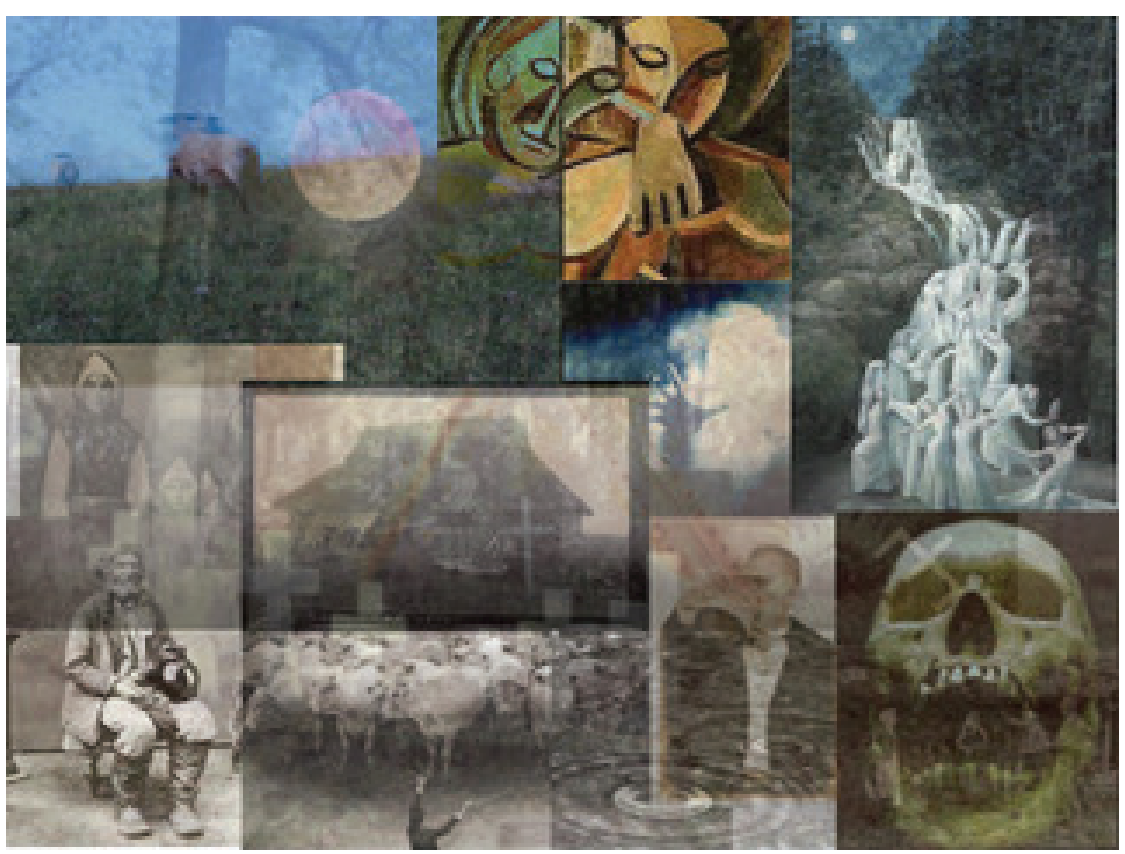

Figure 1: A mood board created by a student

\section{Task 2: Character design}

For the second task, which we carried out in small groups, students were asked to identify dominant traits inherent to the characters of the fictional world, before going on to develop new characters that they felt would fit within it. To complete the task, students were required to analyse the intentions and artistic language of both the writer and the film-makers. To do so, they recollected depictions of characters in the novel and the film. This resulted in a visualization of the new character and a description of his or her personal traits. The task reflects the creative work of a whole film crew students are expected to take on the roles of casting directors, costume designers and make-up artists.

Most of the students perceived the original characters accurately as being greedy, messy, stupid and cruel. Interestingly, the groups employed different strategies: while 
some students came up with characters sharing these features of existing characters, others decided to develop more positive traits, since they felt that 'the story lacks those'. As a result, new characters included a 'strong and skilful hunter', a 'calm and hard-working peasant' and an 'educated priest'. Depictions of the characters matched the visual style of November: to ensure the coherence of the storyworld, students had to choose the appropriate outfit and appearance (old-fashioned clothes, beards, dirty bodies, and so on). For the oral presentation in class, one group even developed a piece of fan fiction describing the relationship of their new character to the already existing ones. The testing showed the genuine interest and investment of the students, who not merely copied the style of previous authors, but also tried to enrich the storyworld through their own contributions.

\section{Task 3: Building a kratt}

The third task features an example close to the practices that Burn (2017: 4) has described as 'media archaeologies' of cultural value in/of media literacy education. The focus is upon cultivating an understanding of the ways in which contemporary media production draws upon past media cultures and allows for the revaluation of earlier works through students' own (digital) transforming practices. The task asked students to search for depictions of kratts (treasure-bearers) in Estonian history of art, folklore and social media, as well as perpetuating and furthering this history of representations with their own creative variations. According to folklore, kratts are built from found objects and are brought to life by the devil in exchange for the owner's soul. The kratt serves its owner by completing any task it is given, which, in the narrative world of November, is mostly stealing. For the first stage of this task, students read excerpts from the novel describing the character, explored different representations within a digital gallery, and searched for other depictions on the internet. Following this, students defined traits common to all representations, and then came up with their own versions (see Figure 2 and Figure 3 for examples). The task aims to show the creativity of the adaptation process: like actual film-makers, students have not only to consider well-known characteristics but also to add something new to the topic.

Figure 2: A student's picture of a Kratt 
Figure 3: A student's picture of a Kratt

Most of the participating students from each of the schools described this assignment in their feedback as being particularly engaging and interesting. It is worth mentioning that this was the only task that produced notably different results in Estonian and Russian classes. Even though Estonian students did not watch the film before performing the task, their versions strangely resembled a kratt of November: all creatures had similar bodies and were composed of household items (buckets, pitchforks, scythes). The Russian students, who did watch the film, came up with more varied ideas - from a mobile app, to creatures reminiscent of Russian folklore. These results can perhaps be explained by the fact that Estonian students derived inspiration from Estonian folklore, literature and art, which also inspired the creators of November. Most of the Russian students, however, were not familiar with the concept of kratt and used other sources to compensate for this lack: Russian folklore, anime cartoons and developments in technology. In this way, our testing raised questions as to the role of cultural memory in the perception of artistic texts: judging by the results from Russian students, cultural experience can affect mental images even more strongly than recently encountered representations belonging to another cultural tradition.

\section{Analysis}

Our analysis of the testing process is based on the data collected through participant observations, interviews with teachers and written feedback from students. The feedback confirmed the innovativeness of the project in technological and methodological terms, at least in a local context. Most of the students enjoyed the group tasks, which required creativity and social interaction: drawing characters and coming up with new ideas were the most popular activities, according to the feedback. At the same time, some students mentioned that they would have benefited if the course had included even more creative tasks and less instruction. This feedback influenced the design of the following courses by our group, which became more practice-oriented.

The testing was considered successful in all schools, even though it did not always proceed as planned. For instance, it appeared that not every class was well-equipped for performing tasks on digital devices: in some schools, students were unable to use laptops or tablets, while others did not even have a screen and 
a projector. Consequently, the tasks were modified on the spot: instead of reading excerpts themselves, students listened to the instructor reading, and some of the tasks were completed with paper and pen. This complication encouraged us to offer analogue solutions in addition to digital ones wherever possible, indicating these also in the teacher's guidelines on the website.

Even though the course was originally designed for teaching cinematic adaptations, in the Russian-speaking classes it turned in many respects into a course on Estonian culture. The initial reception of the film differed much more than we had expected between Estonian and Russian students: the latter experienced almost a culture shock due to the overall dark atmosphere, and scenes including nudity, violence, obscene language and unfamiliar irony. These controversial aspects of the material distracted attention from analysis of the adaptation to a discussion of its content. In order to address this issue, we decided to devote some time to explaining aspects of Estonian culture and artistic style. Drawing upon Juri Lotman's (1997) idea that cultures should be analysed in comparison with other cultures, we tried to establish connections between similar aspects in different cultures. As a result, we found that the attitudes of Estonian and Russian students towards the material conformed after taking the course, which was then reflected in the feedback. The Education on Screen platform attempts to integrate formal education, students' everyday media practices and the 'third space' as operationalized in educational contexts by Potter and McDougall (2017). As such, it appears to function as a fruitful tool not only for teaching media literacies, but also for developing cultural literacies. While this aspect of the project ended up being a welcome side effect in our first edition, it was further enforced in the second, which featured an interactive map of the storyworld. The introduction of multimodal materials and activities to the process of learning proved to be especially beneficial for Russian students. Whereas reading a novel or watching a film can be energy-consuming or difficult, multimodal and game-like practices helped to establish a more meaningful connection with the object of learning.

\section{Case study: History on Screen}

\section{Aims and structure}

History on Screen is based on an autobiographical trilogy: Comrade Child and Grownups (Seltsimees laps ja suured inimesed, 2008), Velvet and Sawdust (Samet ja saepuru, ehk, Seltsimees laps ja kirjatähed, 2009) and The Touch of a Woman's Hand (Naisekäe puudutus, ehk, Seltsimees laps ja isa, 2018) - an Estonian literary classic by Leelo Tungal - and its cinematic adaptation by Moonika Siimets. The film The Little Comrade (2018) was created in honour of the 100th anniversary of the Republic of Estonia, winning a place among the projects that received state support in a competition organized for a filmic celebration of the anniversary. The novels describe the tragic era of Stalinist repression through the eyes of a small girl, whose mother has been deported to Siberia. The subsequent educational project History on Screen was designed primarily for history classes, but it can also be used in interdisciplinary education.

Film can play a twofold role in history education. First, it can be seen as an illustration of the past. While watching a film, students get acquainted with a period and analyse its depiction in terms of historical fidelity. Second, however, film can be a starting point for discussions about the role of different texts in our understanding of the past. In line with the ideas of German history scholar Jörn Rüsen (1994), we 
argue for a multifaceted narrative that does not portray a nation's past as a single and singular story, but as a collection of different voices and perspectives.

History on Screen replicates the model of Learning on Screen - three theoretical chapters (Time in Story, Story in Time, and Time and Story in Culture) - supplemented with a map of the storyworld. Guided by our previous experience, we structured the course around creative and practice-oriented tasks. As with Learning on Screen, the site combines tools for learning about cultural heritage and developing literacies. To provide a deeper engagement with history, we use various digital formats in our project, from archive materials and book covers to video lectures and games. As a result, students not only learn facts about Stalinist culture, but are also able to understand how the past is mediated through different sources. Whereas the tasks for Literature on Screen are mainly used to illustrate theoretical concepts, History on Screen follows a different logic, whereby the theory is used to support the practice, and not vice versa. All the tasks can be roughly subdivided into three groups: tasks with instant feedback, open tasks and creative problem-solving tasks. The map serves a more important function in this case, since it includes not only verbal comments on the cultural context, but also short videos featuring expert opinions and additional interactive tasks.

The first section - Time in Story - explores the idea that our understanding of the past is influenced by a great number of sources, formal school education being the dominant one. Apart from analysing the role of official narratives in the construction of memory (for example, history textbooks, academic articles and teachers' lectures), students are encouraged to look at less formal (yet still significant) sources, such as oral stories passed on by previous generations, mass culture products and works of art. Rather than ranking sources in order of their perceived truthfulness, we offer tools for defining their role in the cultural mediation of the past. Among other tasks, students are asked to explore different artistic representations of the Stalinist era and to deconstruct their own mental image of a historical event.

The second section - Story in Time - explores the principles by which stories are preserved and replicated throughout history. People are viewed not as passive receivers of historical facts, but as active participants, in both the reception and the dissemination of different presentations of the past. This section analyses the role of perspective, connections between fiction and memoir, and historical symbolism in artistic works. Practical tasks include the creation of a timeline of the story of Comrade Child, retelling a story from different perspectives and exploring one's own family history.

The third section - Time and Story in Culture - deals with the problems of cultural memory and conflicts of memory. Here, the theoretical aspects of the work explore the mechanisms of preservation and transformation of historical knowledge under the influence of power relations. In this section, students are asked to visualize a scene from the script, create a book trailer and come up with a solution that would help to solve a local memory conflict surrounding the monument for a Soviet soldier.

The interactive map in History on Screen features eight objects related to the depicted world of Stalinism. While some of the topics are more or less universal, such as the cult of personality or experiences of repression, others are more specific to the Soviet Estonian context - for instance, the idea of vene värk, an Estonian term (which literally means 'a Russian thing') used to refer to things done improperly and to dysfunctional objects. Each point on the map is illustrated by a brief video lecture, and an interactive task or game. Among other activities, students are asked to translate words from Soviet 'newspeak' or find out the meanings of ideological Stalinist songs. 


\section{Testing}

Testing of the course took place in autumn 2017 with 30 students, half studying in Estonian-language schools and the other half studying in Russian-language schools. The principal aims of the course were to understand how we remember the past and to explore the role of different cultural languages in this process. Testing included three day-long learning sessions and several days of independent work. Students had the opportunity to participate in workshops, group tasks and lectures from expert commentators. At that time, neither the film The Little Comrade nor the website were available to the public. Rather than testing History on Screen in its entirety, our team collected data on the effectiveness of different tasks and formats. Guided by the experience gained during the three weeks of testing, we spent the following months improving and modifying the content for the website, which was then launched in summer 2018.

The programme of the course included several creative tasks that were performed either in groups or individually. While the course was not focused on film education specifically, the following analysis presents only the tasks relevant to this subject. Prior to the first in-class session, students described their images of the Soviet era in an essay - Task 1. For Task 2, students were asked to create a timeline representing Soviet history through artistic texts. Task 3 consisted of visualizing a scene for the film on the basis of the script.

\section{Task 1: Essay}

For the first task, students were asked to write an essay beginning with the phrase 'I know that in the Soviet era ...'. The aim of this first assignment was to collect insights into the participants' thoughts and experiences about events that took place before they were born, as well as to warm them up for the future work. Apart from sharing knowledge about the Soviet Union, students were encouraged to deconstruct their own memory and to analyse where the information originated. Essays were written individually at home during one week before the first session. This task can be linked to a stage of development in film-making in that, rather than being based solely on a literary source, each cinematic adaptation is also influenced by the subjective view of its author, as well as by its current cultural context.

The reflective essays helped to position students' own views and cultural knowledge about a period of time. Out of 30 participants in the testing process, 27 managed to complete the task. Most essays were based on knowledge shared by parents and grandparents of the students. While participants mentioned articles and artistic works as their sources in a few instances, in most cases the information was presented as being part of common knowledge. The material selected in the essays and its connotations was seemingly very different between Russian-language and Estonian-language students. Only one keyword - 'deficit' - appeared to be equally relevant for both (appearing in eight essays by Estonian students and ten essays by Russian students). The essays written by Estonians included significantly more negative connotations: students wrote about fear (four mentions), travel ban (three), Christmas celebration ban (three), poor life (two), depression (one), deportation (one) and strict rules (one). Some other aspects (for instance, pioneers or panel buildings) were discussed as being more neutral. Russian students were more focused on the positive features of Soviet life, such as communality, stability, equality, free social services, safety and the high level of education (each feature was mentioned at least once). All these aspects belong to Soviet propagandistic discourses, which remain strong 
in contemporary Russia, but have little relevance for Estonian-speaking students. Among negative phenomena, some Russian students discussed totalitarianism (three mentions), occupation (one), deportation (one), censorship (one) and the iron curtain (one). A significant number of essays in both groups included a comparison between the Soviet time and contemporary life: at least five Russian students wrote that life used to be better in some respects. The analysis of works has shown a gap between the attitudes of Russian and Estonian students, even though all of them belonged to the same educational system. As a result, we suggest that ideas and knowledge acquired informally can play a dominant role in one's image of the past. Keeping in mind the artistic focus of the programme, we focused our work on facilitating the discussion between the polarized positions.

\section{Task 2: Timeline}

Timelines allow events to be put in order and different levels to be juxtaposed from global history to private life. During the testing process in class, students were asked to choose various artistic texts (films, books, paintings, architecture, and so on) representing the decades of Soviet history. Students completed the task in small groups by using Timetoast (www.timetoast.com), an online application for creating interactive timelines. Digital timelines were projected onto screens and discussed in class. The task helped students to understand the role of artworks, including films, in remembering the past. Students were encouraged to reflect on the importance of different texts in cultural memory, and to think what makes some of them more popular and powerful than others.

The task was performed in mixed groups including both Estonian and Russian students. Due to this fact, the assignment appeared to be more difficult and unpredictable, since the students had to find not only common ground, but also a common language. The outcome of the task was largely dependent on group dynamics. For instance, a group with two Russian girls leading the discussion came up with a timeline consisting almost entirely of artistic works associated with Soviet Russia. However, most timelines included references to both a more universal Soviet context and a more specific Estonian one. While timelines were largely based on films and books, some of them also included paintings, cartoons, monuments and architectural objects. Interestingly, timelines also featured some contemporary Estonian films, while all the Russian artistic works belonged to the Soviet period. The results of the task supported the conclusions arising from the analysis of the first assignment: in the majority of Estonian artistic works, the Soviet era had distinctly negative connotations, while in Russian works it had the opposite.

\section{Task 3: Scene visualization}

The third assignment was prepared by students in groups during independent work outside class time. Groups of five students were asked to imagine that they were hired by the director of The Little Comrade to collect background material for shooting the scenes. Students were asked to read excerpts from the script and visualize corresponding places: a hairdressing salon, school, living room or kitchen. The objective was to provide an authentic image of the 1950s in Soviet Estonia - that is, to find relevant pictures of furniture, objects and clothing. To complete the task, students were encouraged to use a list of digital archives. Such a task can be linked to a pre-production stage in film-making, in that students are asked to find depictions of a suitable location, setting and aspects of production design. 
Most teams successfully fulfilled the task, except for one group that evidently did not understand the assignment and presented a description of a room in written form. All other students made use of digital archives and tried to find relevant images. The collages (see Figure 4 for an example) mostly consisted of historical pictures, while only a few contemporary photographs were used to point towards less specific elements of the story (for instance, a flock of birds in the sky).

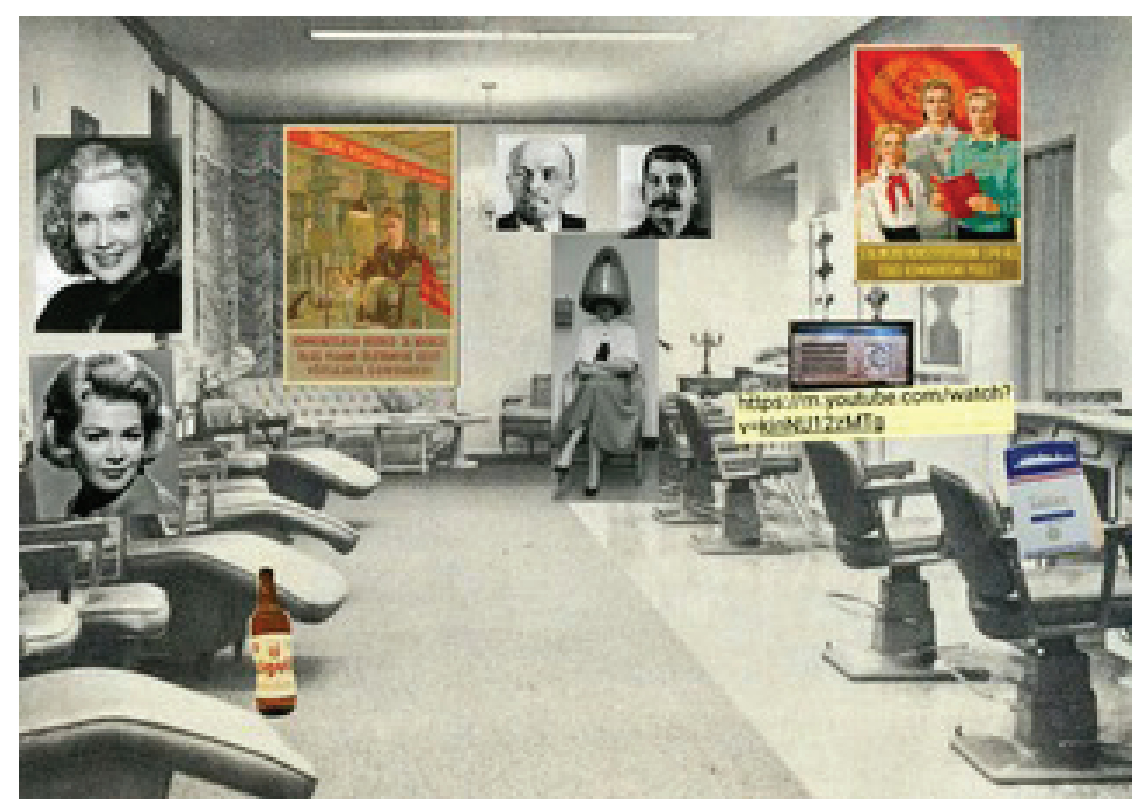

Figure 4: Student collage

Some students not only included objects mentioned in the story, but also provided additional material to give a better feeling of the time: portraits of Soviet leaders, propaganda posters, and even an accompanying soundtrack. Even though we had not asked for it, some teams performed extra work to integrate objects into their pictures to make them look more coherent and realistic. However, the background research in the students' work was not always sufficiently thorough, leading to some ambiguous and often amusing results. For instance, one team accidentally used a photograph of an SS officer instead of a KGB officer, while another group chose a picture of a boy in an Adidas T-shirt - hardly imaginable in a rural Soviet school in the 1950s.

\section{Analysis}

While testing of the online environment of History on Screen itself is yet to be conducted, the three-week experience helped to reveal some of the stronger and weaker aspects of the project. In feedback collected via an online survey, many students expressed their satisfaction with the course, which they viewed as a refreshing break from their school routine. Moreover, many participants appreciated the opportunity to work in groups with students from other schools, since Estonian and Russian students rarely share the same spaces. As a result, the opinions expressed by students at the end of the course were not as polarized as they were at the beginning; some students explicitly claimed that they acquired a different perspective on Soviet history. At the same time, a few participants were not particularly happy with the organization of the course: some students found the mere juxtaposition of different opinions without deeper discussion (due to time restrictions) 'not very educative'. The concerns of the 
students were addressed in later iterations of the course and, as a result, some tasks were significantly transformed or eliminated, while new ones were introduced.

The version of the course presented online more actively employs digital tools and materials, which were not always convenient during the class sessions described above. For instance, instead of writing a reflective essay exploring perceptions of the Soviet era (Task 1), students are asked to create a digital, multimodal collage on a historical topic, drawing from films, books, oral stories and other sources. Task 2 was removed, as it left some students puzzled; instead, we decided to use the format of the timeline differently and included some tasks with clearer outcomes on the platform (for instance, students are asked to match artistic works with particular decades, or to put events in historical order). Task 3 remained relatively unchanged aside from some minor adjustments: we placed excerpts from the script online, included links to digital archives and stressed that objects for the collage should definitely belong to a certain time and place: Soviet Estonia in the 1950s.

Since it is not always possible to organize group tasks and creative projects in class, we have also developed simpler exercises that require less time from teachers and students. The platform offers a wide range of tasks that can be explored even without the help of a teacher. Some of them provide instant feedback (such as tests and timelines), while others could be performed individually and discussed in class. None of the tasks require mere recall of facts; rather, students are asked to deduce the answer using their intuition and aspects of theory. Most importantly, the platform provides tools and materials that can be used to analyse different types of historical sources - oral stories, official documents, artefacts and artistic works such as films.

\section{Conclusion}

The Education on Screen platform is based on a holistic approach that allows films to be viewed simultaneously as individual artworks and as inseparable from other cultural forms. It therefore highlights connections between different spheres of culture cinema, literature, history, politics and everyday life. Rather than focusing on separate phenomena, the focus is on processes: students are encouraged to embrace the whole life cycle of cinematic adaptations, as well as different - possibly contradictory - representations of one literary text and one historical event or period. This premise raises questions about teaching and learning literacies, and we have proposed to approach it through the cultural semiotic framework of Lotman's (1971) two ways of learning culture.

The first way implies learning about a corpus of canonical texts that constitute the core of a given cultural space. For example, one would need to learn about Hamlet in order to understand English culture, or to learn about Harry Potter in order to understand contemporary young adult literature. At the same time, the cultural semiotic understanding of text is not only structural but processual (Lotman, 2001: 63-81), which implies that the meaning and function of a text are subject to change along with the cultural context. As a result, the paratexts (Genette, 1997) in different media and modalities form a definitive part of the existence of a text in culture. So, instead of merely juxtaposing films and the novels on which they are based, Literature on Screen focuses on texts that are often excluded from school education, but are constitutive in the process of film creation and its reception in culture: the script, the storyboard, the reviews, the fan fiction, and so on. Comparably, History on Screen guides students to notice the multiplicity of perspectives represented in historical films and other narratives, and how their interpretation changes through time. As it 
transpired, such multimedial and multimodal approaches to teaching and learning about texts were especially beneficial in the Russian-language schools within the Estonian educational system. For example, concentrating on the aspects of the film November that seemed alien to the Russian students (visualities, verbal language usage, mythological background, and so on), and offering ways of reflecting on the text through multimodal activities more familiar in the students' everyday media environment, allowed (what we found initially surprising) different attitudes towards the film between Russian and Estonian students to eventually conform after the course. In effect, a project conceived as a framework for teaching and learning about processes of film adaptation of literary texts simultaneously began to function as a more general course in Estonian culture. Something similar happened during the course organized in preparation for the History on Screen project. After tasks and discussions revolving around the transmedial mediation of the past in culture, and students' reflections about the mediated ways that their understanding of history is formed, Estonian-language and Russian-language students were better able to put their hitherto conflicted understandings of the Soviet past into dialogue.

The second way of learning culture implies the cultivation of skills related to information production and reception that are needed for navigating a given cultural space. This approach is also present to a large extent in the concept of 'new literacies' (Leu et al., 2017) in the context of the development of new media technologies. In our experience with Education on Screen, however, the skills that students perceived as valuable did not belong exclusively to the digital sphere. Multimodal creative ways for self-expression and collaboration with other students with different cultural backgrounds turned out to be the most esteemed by students whose school settings were still relatively more verbocentric and individualist. These responses led us to develop analogue alternatives for digital tasks on the project's online platform, and to explain these in the guidelines for teachers linked with each project. By combining these two approaches, we have aimed to participate in the process of paving the way for students in Estonia to act as cultural agents and participants in film culture in the most general sense.

\section{Notes on the contributors}

Maarja Ojamaa $(\mathrm{PhD})$ works as a researcher at the Department of Semiotics at the University of Tartu (UT) and at Tallinn University's (TLU) Baltic Film, Media, Arts and Communication School (BFM), where she is also a member of TLU Centre of Excellence in Media Innovation and Digital Culture (MEDIT). Her research interests include the transmedial mechanisms of cultural memory and educational (re)usage of cultural heritage. She has also been developing digital learning materials for high school students with the Education on Screen group at UT.

\footnotetext{
Alexandra Milyakina is a PhD student in semiotics at the University of Tartu, Estonia, researching digitization of literary education in the context of cultural autocommunication. Alexandra's research interests include literary education, semiotics of culture, transmedia and digitization. Alexandra is a part of the Education on Screen research and development group producing digital learning projects for high school students. The group has created three platforms focused on teaching literature, history and identity. Alexandra has an MA degree in semiotics, an MA in comparative philology and a BA in journalism.
} 


\section{Filmography}

November (EE 2017, Rainer Sarnet)

The Little Comrade (EE 2018, Moonika Siimets)

\section{References}

Burn, A. (2017) 'Revisiting the popular arts: Media education, cultural values and cultural production'. In De Abreu, B.S., Mihailidis, P., Lee, A.Y.L., Melki, J. and McDougall, J. (eds) International Handbook of Media Literacy Education. New York: Routledge, 19-32.

Burn, A. and Durran, J. (2007) Media Literacy in Schools: Practice, production and progression. London: Paul Chapman Publishing.

Cannon, M., Potter, J. and Burn, A. (2018) 'Dynamic, playful and productive literacies'. Changing English: Studies in Culture and Education, 25 (2), 180-97.

Chambers, J., Reid, M. and Burn, A. (2018) 'Editorial: Welcome to the Film Education Journal'. Film Education Journal, 1 (1), 1-4.

Genette, G. (1997) Paratexts: Thresholds of interpretation. Trans. Lewin, J.E. Cambridge: Cambridge University Press.

Jakobson, R. (1981) 'The dominant'. In Selected Writings: Volume 3: Poetry of grammar and grammar of poetry. Ed. Rudy, S. The Hague: Mouton Publishers, 751-6.

Kivirähk, A. (2000) Rehepapp, ehk, November. Tallinn: Varrak.

Leu, D.J., Kinzer, C.K., Coiro, J., Castek, J. and Henry, L.A. (2017) 'New literacies: A dual-level theory of the changing nature of literacy, instruction, and assessment'. Journal of Education, $197(2), 1-18$.

Lotman, J. (1971) 'Проблема «обучения культуре» как ее типологическая характеристика' ['The problem of "learning culture" as its typological feature']. Труды по знаковым системам ['Sign Systems Studies'], 5, 167-76.

Lotman, J. (1981) Semiotics of Cinema. Ann Arbor: University of Michigan.

Lotman, J. (1997) 'О типологическом изучении литературы' ['On the typological study of literature']. In O русской литературе ['On Russian Literature']. St. Petersburg: Iskusstvo-SPB, 766-74.

Lotman, Y.M. (2001) Universe of the Mind: A semiotic theory of culture. Trans. Shukman, A. London: I.B. Tauris.

Manovich, L. (2001) The Language of New Media. Cambridge, MA: MIT Press.

Ojamaa, M., Torop, P., Fadeev, A., Milyakina, A., Pilipovec T. and Rickberg, M. (2019) 'Culture as education: From transmediality to transdisciplinary pedagogy'. Sign Systems Studies, 47 (1-2), 152-76.

Parry, B. (2010) 'Helping children tell the stories in their heads'. In Bazalgette, C. (ed.) Teaching Media in Primary Schools. London: SAGE Publications, 89-101.

Potter, J. and McDougall, J. (2017) Digital Media, Culture and Education: Theorising third space literacies. London: Palgrave Macmillan.

Rüsen, J. (1994) 'Geschichtskultur als Forschungsproblem'. In Historische Orientierung: Über die Arbeit des Geschichtsbewusstseins, sich in der Zeit zurechtzufinden. Köln: Böhlau, 235-45.

Saldre, M. and Torop, P. (2012) 'Transmedia space'. In Ibrus, I. and Scolari, C.A. (eds) Crossmedia Innovations: Texts, markets, institutions. Frankfurt am Main: Peter Lang, 25-44.

Scolari, C.A. (2013) 'Lostology: Transmedia storytelling and expansion/compression strategies'. Semiotica, 195, 45-68.

Siegel, M. (1995) 'More than words: The generative power of transmediation for learning'. Canadian Journal of Education, 20 (4), 455-75.

Strauven, W. (2011) 'The observer's dilemma: To touch or not to touch'. In Huhtamo, E. and Parikka, J. (eds) Media Archaeology: Approaches, applications, and implications. Berkeley: University of California Press, 148-63.

Suhor, C. (1984) 'Towards a semiotics-based curriculum'. Journal of Curriculum Studies, 16 (3), 247-57.

Torop, P. (2015) 'Cultural semiotics'. In Sharifian, F. (ed.) The Routledge Handbook of Language and Culture. London: Routledge, 170-80.

Tungal, L. (2008) Seltsimees laps ja suured inimesed: veel üks jutustus õnnelikust lapsepõlvest. Tallinn: Tänapäev.

Tungal, L. (2009) Samet ja saepuru, ehk, Seltsimees laps ja kirjatähed. Tallinn: Tänapäev.

Tungal, L. (2018) Naisekäe puudutus, ehk, Seltsimees laps ja isa. Tallinn: Tänapäev. 